\title{
The impact of vehicle dynamic parameters on the exhaust emissions in RDE tests
}

The article compares driving test data using the latest legislative proposals applicable to passenger cars with different drives. For this purpose, cars of one type were selected, meeting the same exhaust toxicity standard (Euro 6c) and differing in used internal combustion engines (with spark-ignition, compression-ignition and hybrid drive). Several measurements were performed on the same test route in accordance with the RDE test guidelines, which requires a several of criteria to be met. These criteria include the length of the measuring sections, their overall timeshare and the dynamic characteristics of the drive. A portable emissions measurement system (PEMS) was used to record the engine and vehicle operating parameters and to measure the exhaust emissions during tests. This allowed for the monitoring of parameters such as: load value, engine speed and vehicle velocity. Then the obtained results were analyzed for their compatibility with the RDE procedure requirements. By determining the road emission of individual harmful compounds for all vehicles and the dynamic parameters of drive (relative positive acceleration and product of speed and positive acceleration) in various phases of the road test it was possible to compare them. On this basis, the impact of dynamic conditions of road tests on the obtained results of the road exhaust emission of harmful compounds for passenger cars with various drives was defined.

Keywords: exhaust emission, passenger cars, road tests, Real Driving Emissions

\section{Introduction}

Emission standards are established for the control of pollutants emitted from motor vehicles worldwide . Most regions also set the limits on carbon dioxide emissions, which are directly related to fuel consumption [1, 31]. Exhaust emission values are measured in laboratory conditions (for passenger cars on the chassis dynamometer) in a fixed certification test. This part of the vehicle certification process is responsible for its "environmental performance" and is the same for all passenger cars. The chassis test is responsible for the "most likely" road conditions, and performing the same tests for all vehicles entitles to compare the emission results between them. However, nowadays, more and more attention is given to road tests (which is already reflected in the proposed European Union emission regulations), known as RDE tests, using mobile research equipment type PEMS (Portable Emission Measurement System) [23, 28, 29]. The latest research on emission of pollutants from motor vehicles in traffic conditions reflect the actual ecological performance of vehicles [13-15, 21, 30]. Most attention is given to the possibility of using such tests to calibrate the engines in such a way as to reduce emissions not only during the certification test, but also in the entire range of engine operation. The authors of papers [12] pointed out that new research in real traffic conditions, currently simulated in various research tests (NEDC - New European Driving Cycle [26], CADC - Common Artemis Driving Cycles, WLTP - Worldwide Harmonized Light Vehicles Test Procedure [25]), may increase the emission of nitrogen oxides from vehicles. They postulated that it is necessary to make changes in the vehicles software, stating that these changes will be successful only for vehicles fitted with spark-ignition engines. Vehicles equipped with compression-ignition engines will require further investments to increase the effectiveness of the exhaust gas aftertreatment through the use of new methods of reducing the concentration of nitrogen oxides (e.g. SCR - Selective Catalyst Reduction system) [24].
Authors of the articles [9, 10], who compared road emissions in real driving conditions with the use of PEMS analyzers with results obtained using the program COPERT, arrived at the same conclusions [16]. It was found that in the speed range of $20-120 \mathrm{~km} / \mathrm{h}$, the calculation results obtained in this program are higher by about $10 \%$ for such quantities as fuel consumption and the emission of hydrocarbons to values from road tests. However, with regard to the emission of nitrogen oxides the data from COPERT are understated by about $30 \%$.

Comparative emission studies of Euro 5 emission class vehicles carried out in the laboratory on a chassis dynamometer [7] in various driving tests (including NEDC, CADC and WMTC - Worldwide Motorcycle Test Cycle) also confirmed the results previously characterized. It was found that for vehicles with gasoline engines the emissions of carbon monoxide does not exceed $1 \mathrm{~g} / \mathrm{km}$ (permissible Euro 5 limit is also $1 \mathrm{~g} / \mathrm{km}$ ), emission of hydrocarbons does not exceed $10 \%$ of the limit $(0.1 \mathrm{~g} / \mathrm{km})$ and the emission of nitrogen oxides is equivalent to approximately $20 \%$ of the limit $(0.06 \mathrm{~g} / \mathrm{km})$. It was also pointed out that the vehicles with compression-ignition engines far exceed the acceptable emission limits of nitrogen oxides - the obtained values exceed the exhaust emission limit approximately 4 times (emission limit values for nitrogen oxides in Euro 5 is $0.18 \mathrm{~g} / \mathrm{km})$.

Studies in road traffic conditions draw attention to significant emissions of particulate matter, mainly in nanoparticle range from combustion engines also those powered by alternative fuels (e.g. natural gas) [17]. The article also emphasizes considerable mileage of the vehicle using alternative fuels, which in turn causes an 8 times increase in emitted particle number for vehicle with a mileage of $500,000 \mathrm{~km}$ compared to the vehicles with mileage of $75,000 \mathrm{~km}$.

With regard to the accuracy of measurements in actual traffic conditions the final result depends on operating conditions of the vehicle and the engine (including the speed of 
other vehicles, road surface, driver's predispositions and his driving style and the aspects of road traffic). These conditions are unpredictable and can significantly affect the outcome of the emissions measurement. According to the data contained in the publications $[6,7,29]$ the greatest impact on the achieved emission results are thermal state of the vehicle (the engine), average speed, driving dynamics and road topography.

The impact of road conditions on the emission results was the main subject of the article, which studied SUVs with petrol and diesel engines under the conditions of varying slope of the road. The authors have attempted to estimate the emission changes of individual components depending on the angle of road inclination. They demonstrated that the change in the road slope of $10 \%$ resulted in a 2-fold change in the emissions for vehicles with sparkignition engines and a 1.5-fold change in emissions for vehicles with compression-ignition engines.

Starting from 2017, the process of type approval of new passenger car models in European Union includes a procedure for measuring emissions in real driving conditions. The European Union regulations (715/2007 [3] and 692/2008 [2]) for RDE tests is a response to the results of studies $[8,11]$ relating to increased emission of nitrogen oxides from vehicles equipped with compression-ignition, although such vehicles met permissible standards in laboratory tests. Under the new rules $[4,5,22]$ for all new type approvals from 1.09.2017, and in the case of newly registered car models from 1.09.2019, the emission of nitrogen oxides measured in traffic conditions will not be allowed to exceed 2.1 times the maximum limit (for Euro 6 that is $80 \mathrm{mg} / \mathrm{km}$ ) or $168 \mathrm{mg} / \mathrm{km}$. However, since 1.01 .2020 for a new type approval (and since 1.01.2021 for new model registrations) this ratio will be reduced to 1.5 . It means that the maximum emission of nitrogen oxides cannot exceed $120 \mathrm{mg} / \mathrm{km}$ (Fig. 1).

\begin{tabular}{|c|c|c|c|c|c|c|c|}
\hline 2015 & 2016 & 2017 & 2018 & 2019 & 2020 & 2021 & 2022 \\
\hline \multicolumn{3}{|c|}{ Euro 6b } & \multicolumn{2}{|c|}{ Euro 6c } & \multicolumn{3}{|c|}{ Euro 6d } \\
\hline \multicolumn{3}{|c|}{ NEDC } & \multicolumn{5}{|c|}{ WLTC } \\
\hline \multicolumn{3}{|c|}{$\begin{array}{c}\text { Development and } \\
\text { measurement phase }\end{array}$} & \multicolumn{5}{|c|}{ Conformity Factor (CF) } \\
\hline
\end{tabular}

\begin{tabular}{|c|c|}
\hline RDE for $\mathrm{CO}, \mathrm{NO}_{\mathrm{x}}, \mathrm{PN}$ emissions: \\
EC 427/2016 and EC 646/2016
\end{tabular}

Fig. 1. RDE tests requirements in Europe [4, 5]

\section{Research aim}

The aim of the research was to compare the exhaust emissions in relation to the dynamic parameters of RDE tests for vehicles with different drives. This comparison was made during the RDE tests on the same test route divided into urban, rural and motorway sections The measurements were performed for the same category of the vehicle equipped with gasoline and diesel engines and for hybrid drive.

\section{Research methodology}

\subsection{Test route}

The research route has been designated in accordance with RDE requirements and divided into 3 sections: urban, rural and motorway. The driving distances and shares of individual portion of the test have been chosen so that they meet the requirements described in the Commission Regulations 2016/427 [4] and 2016/646 [5]. The total distance of the test route was approximately $80 \mathrm{~km}$ and the average velocity was about $45 \mathrm{~km} / \mathrm{h}$ (Fig. 2). The share of individual sections in test routes is presented in Fig. 3.

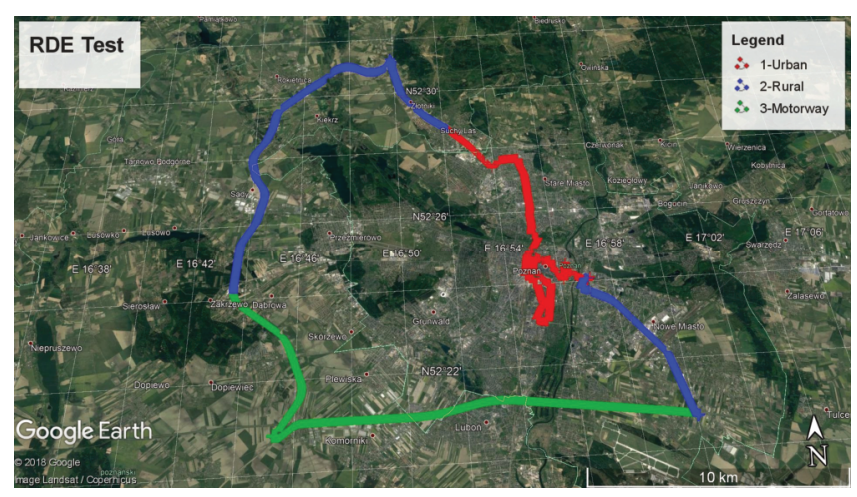

Fig. 2. The research route with marked RDE test phases

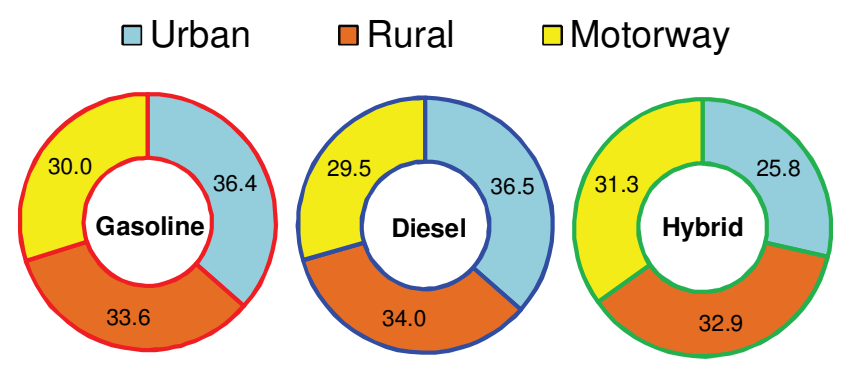

Fig. 3. The share of urban, rural and motorway sections in test routes

\subsection{Research objects}

The objects of research were passenger cars of the same make and type but equipped with various drive (Table 1).

Table 1. Characteristics of the research object

\begin{tabular}{|l|c|c|c|}
\hline \multicolumn{1}{|c|}{ Parametr } & Gasoline & Diesel & Hybrid \\
\hline $\begin{array}{l}\text { Displacement volume } \\
{\left[\mathrm{dm}^{3}\right]}\end{array}$ & 1.6 & 1.4 & 1.8 \\
\hline $\begin{array}{l}\text { Number of cylinders/ } \\
\text { valves }\end{array}$ & $\mathrm{R} 4 / 16$ & $\mathrm{R} 4 / 8$ & $\mathrm{R} 4 / 16$ \\
\hline $\begin{array}{l}\text { Maximum power } \\
\text { at engine speed } \\
{[\mathrm{kW} / \mathrm{rpm}]}\end{array}$ & $\begin{array}{c}97 / \\
6400\end{array}$ & $\begin{array}{c}66 / \\
3800\end{array}$ & $\begin{array}{c}73 / 5200- \\
\text { gasoline; } \\
100 \text { (hybrid) }\end{array}$ \\
\hline $\begin{array}{l}\text { Maximum torque } \\
\text { at engine speed } \\
{[\mathrm{Nm} / \mathrm{rpm}]}\end{array}$ & $160 /$ & $205 /$ & $\begin{array}{c}142 / \\
4000\end{array}$ \\
\hline $\begin{array}{l}\text { Volume power ratio } \\
{\left[\mathrm{kW} / \mathrm{dm}{ }^{3}\right]}\end{array}$ & 60.6 & 47.0 & 55.5 \\
\hline Curb weight [kg] & 1240 & 1250 & 1415 \\
\hline
\end{tabular}




\subsection{Exhaust emission measurement}

The measuring systems are presented in Fig. 4. A portable Semtech DS analyser [27] was used for the measurement of exhaust emissions from vehicles. It allowed measurements of $\mathrm{CO}, \mathrm{CO}_{2}, \mathrm{HC}$ and $\mathrm{NO}_{\mathrm{x}}$. In terms of benchmarking and quality control, zero-span checks were performed before and after each measurement. Linearisations of the equipment were carried out every three months. Post-processing plausibility checks were made on all data, focusing on $\mathrm{CO}_{2}$, to ensure that the data collected were realistic. A portable AVL condensation particle counter was used to measure the particle number. The emissions measurement equipment had a maximum mass of $69 \mathrm{~kg}$ (Gas PEMS - $25 \mathrm{~kg}$ [19], PN PEMS - $23 \mathrm{~kg}$ [20]), together with an additional power supply (generator) $-21 \mathrm{~kg}$.

a)

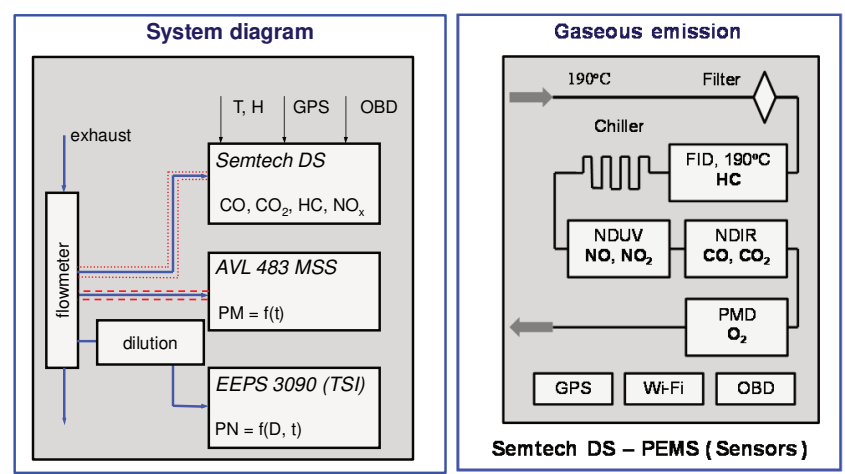

Fig. 4. The measuring systems used for testing under real driving conditions

\section{Results}

\subsection{Validity of RDE tests}

In Figure 5 results from all test drives are shown using the $\mathrm{V}=\mathrm{f}(\mathrm{S})$. It shows the division of the research route into 3 portions: urban $(\mathrm{V}=0-60 \mathrm{~km} / \mathrm{h})$, rural $(\mathrm{V}=60-90 \mathrm{~km} / \mathrm{h})$ and motorway $(\mathrm{V}>90 \mathrm{~km} / \mathrm{h})$. Despite the similar research route, not only the velocity results, but also its average values in the individual test portions are not the same. The driving parameters defined by acceleration, constant velocity, braking and stopping are similar. These parameters are systemized in Fig. 5. The average values were: for acceleration $-30 \pm 0.2 \%$, constant driving velocity $-17.75 \pm 0.25 \%$, braking - $33.3 \pm 0.46 \%$, and for stopping from $19 \%$ to $21.5 \%$.

Detailed requirements in accordance with the RDE road test standard are given below, where the verification of defined earlier individual driving parameters conformity has been demonstrated and their values are compared also giving the permitted range (if required) and with mean values also determined.

The analysis of test distance data in the urban portion showed that the tests of the vehicles equipped with a gasoline and diesel engines were characterized by the longest distance $(27 \mathrm{~km})$ and the test of the hybrid vehicle with the shortest $(26.9 \mathrm{~km})$. However, the values of the driving distance covered for all test drives within the permissible range, i.e. they were more than $16 \mathrm{~km}$ (Fig. 6a). a)

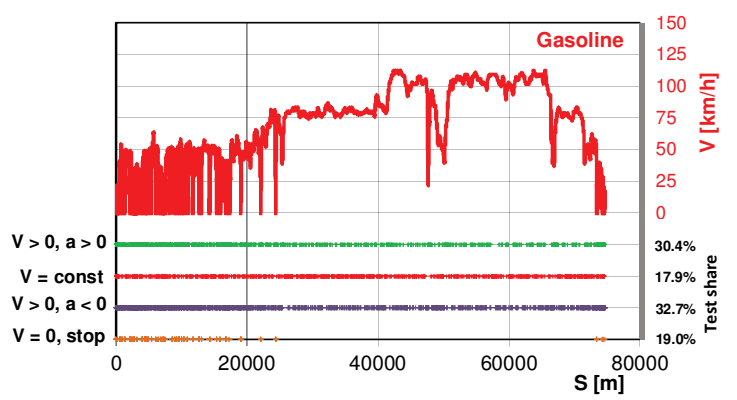

b)

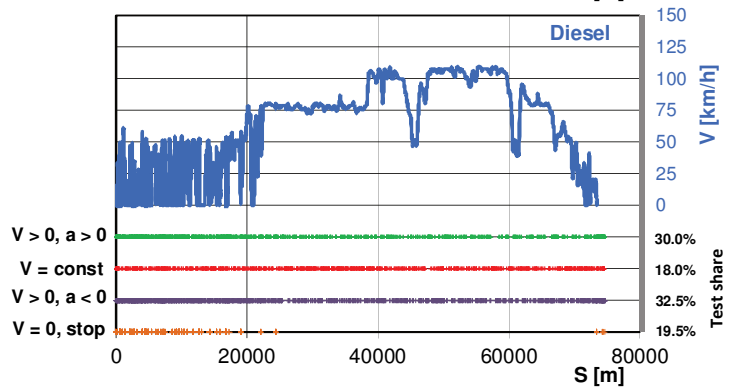

c)

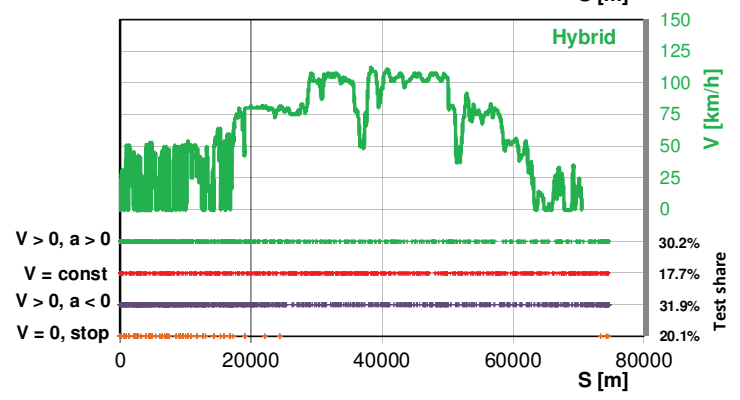

Fig. 5. Velocity profiles and vehicles parameters of motion

The analysis of test distance data in rural portion showed that the tests of the vehicles fitted with gasoline and diesel engines were characterized by the longest distance travelled $(25.1 \mathrm{~km})$ and the test of the hybrid vehicle with the shortest $(24.7 \mathrm{~km})$. The values of the distance covered for all test drives within the acceptable range, i.e. they were more than $16 \mathrm{~km}$ (Fig. 6b). The distance travelled in motorway portion of the test was the longest for the vehicle with the hybrid drive $(23.5 \mathrm{~km})$ and the shortest for the test of vehicle fitted with diesel engine $(21.7 \mathrm{~km})$. The values of the distance covered for all test drives within the permissible range, i.e. they were more than $16 \mathrm{~km}$ (Fig. 6c).

The percentage time share of the urban portion in the drive test was the highest for drive of vehicle fitted with diesel engine $(36.5 \%)$, and the smallest for the vehicle with hybrid drive $(35.8 \%)$. The percentages of urban share of all drives were within the permissible range of $29 \%-44 \%$ (Fig .7a). The percentage time share of the rural portion in the drive tests was the highest for drive of vehicle equipped with diesel engine (34\%), and the smallest for vehicle with hybrid drive $(32.9 \%)$. In this respect all drives were valid within the range of $23-43 \%$ (Fig. 7b). The analysis of percentage time share data of the motorway part showed that the test of the vehicle with hybrid drive was characterized by the highest value $(31.3 \%)$, and the drive of vehicle fitted with diesel engine with the smallest $(29.5 \%)$. The shares of the motorway portion for all vehicles were within the permissible range of $23 \%-43 \%$ (Fig. $7 \mathrm{c}$ ). 
a)

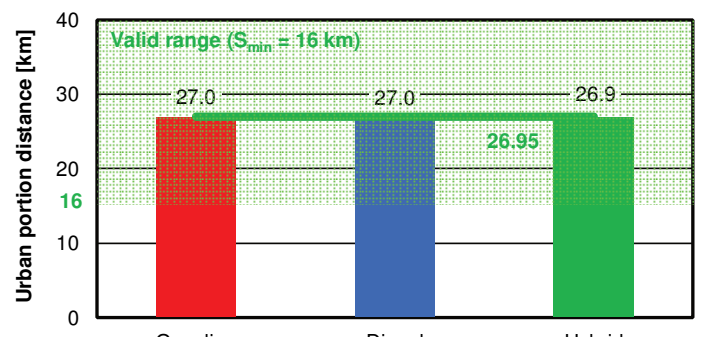

b)

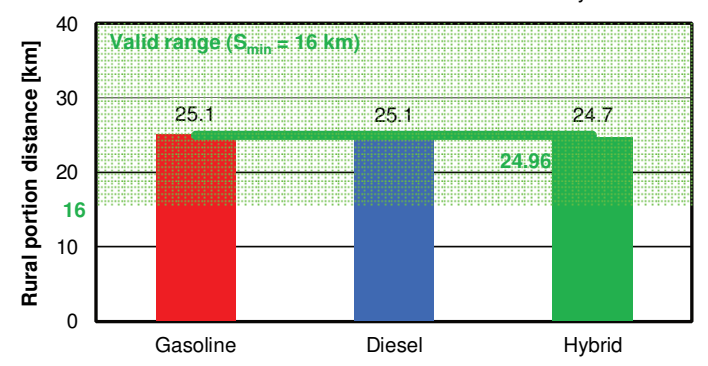

c)

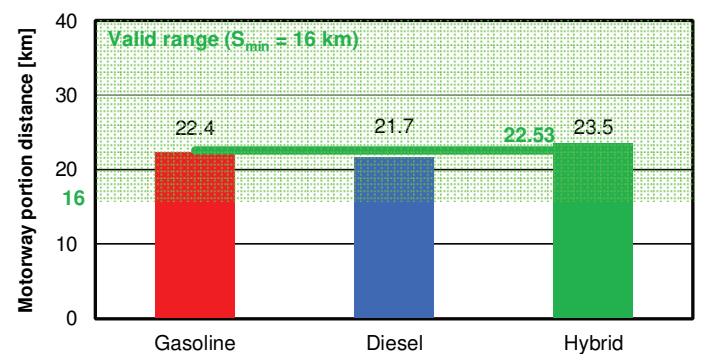

Fig. 6. Travel distance comparison of urban (a), rural (b) and motorway (c) test drives with the minimum distance (required) and the mean value for all vehicles

a)

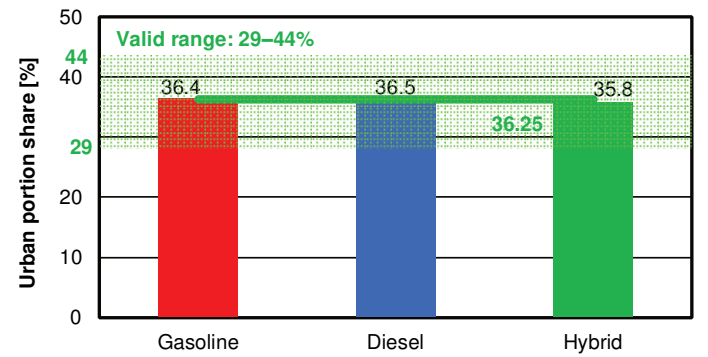

b)

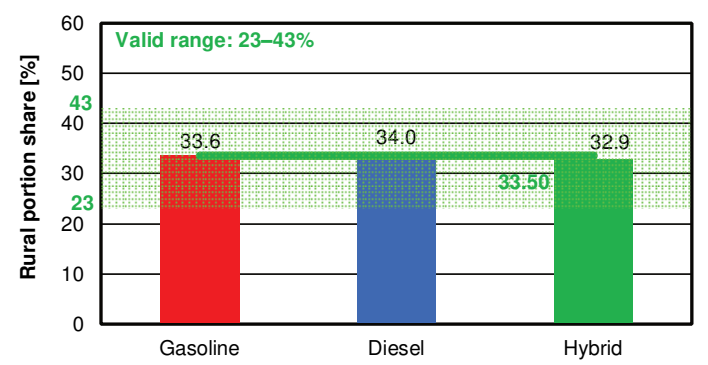

c)

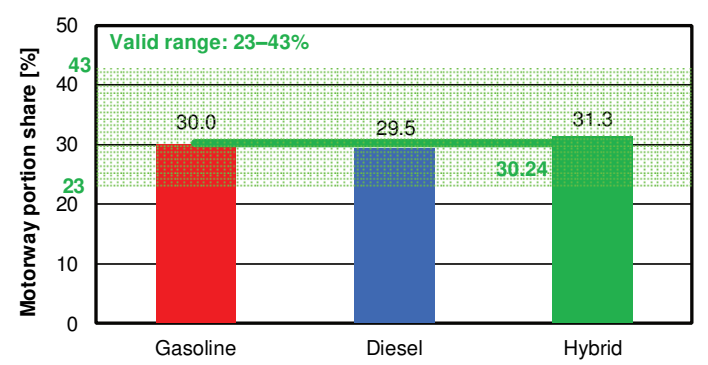

Fig. 7. Test time share comparison of urban (a), rural (b) and motorway (c) test drives with the minimum distance (required) and the mean value for all vehicles
Analysis of the average velocity data in urban test portion showed that the highest values were achieved in drives of vehicles equipped with diesel engine and with hybrid drive $(22.1 \mathrm{~km} / \mathrm{h})$, and the smallest in test of vehicle fitted with gasoline engine $(21.8 \mathrm{~km} / \mathrm{h})$. The average velocity values of all drives were within the permissible range, i.e. between $15 \mathrm{~km} / \mathrm{h}$ and $40 \mathrm{~km} / \mathrm{h}$ (Fig. 8a). Analysis of the average velocity data in rural test portion showed that the highest values was achieved in drive of hybrid vehicle $(77.8 \mathrm{~km} / \mathrm{h})$, and the smallest in drive of vehicle fitted with gasoline engine $(77.1 \mathrm{~km} / \mathrm{h})$. The average velocity for all drives was similar, although the legislator did not specify the permissible velocity range (Fig. 8b). Analysis of the average velocity data in the motorway section showed that the drives were only slightly differed from each other (the dispersion was $0.3 \mathrm{~km} / \mathrm{h}$ at extreme values between $103.8 \mathrm{~km} / \mathrm{h}$ and $104.1 \mathrm{~km} / \mathrm{h}$ ). The legislator did not specify the permissible velocity range (Fig. $8 \mathrm{c}$ ).

a)

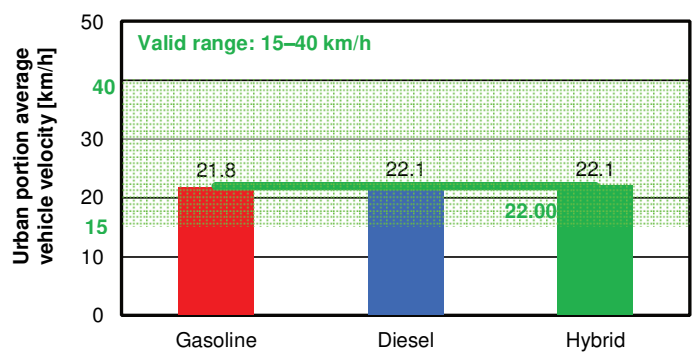

b)

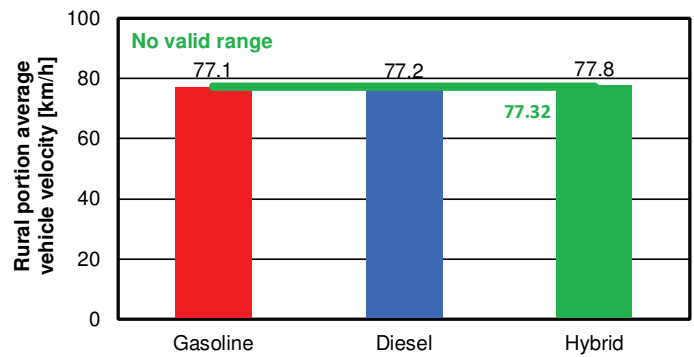

c)

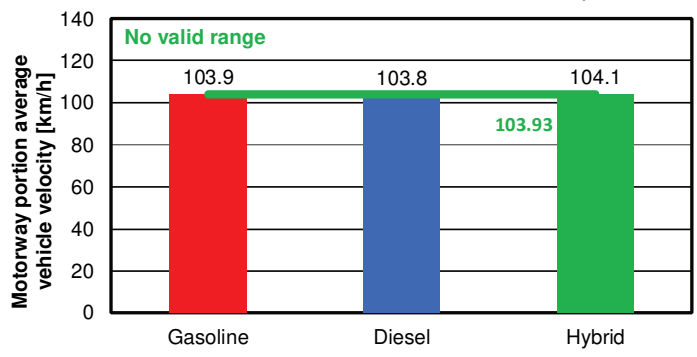

Fig. 8. Average vehicle speed comparison of urban (a), rural (b) and motorway (c) test drives with the minimum speed (required) and the mean value for all vehicles

The duration of the test was the longest for drive of vehicle equipped with gasoline engine (108 $\mathrm{min})$, and the shortest for drives of vehicles fitted with diesel engine and hybrid vehicle (105.4 min). All drives were carried out within an acceptable time range, i.e. from $90 \mathrm{~min}$ to 120 min (Fig. 9).

Analysis of the drive test duration data at velocity above $100 \mathrm{~km} / \mathrm{h}$ in the motorway part showed that the highest value was achieved by the drive of hybrid vehicle (12 min), and the shortest in drive of vehicle fitted with diesel engine (9.9 $\mathrm{min})$. In all drives the values were higher than permissible range, i.e. more than 5 min (Fig. 10). 


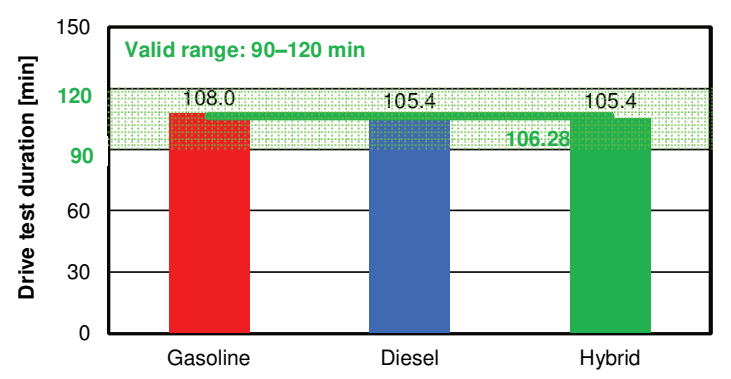

Fig. 9. Comparison of the drive test duration with the limit values (required) and mean values for all vehicles

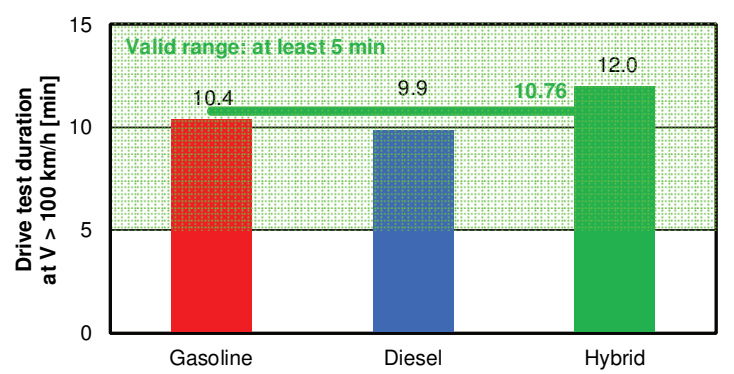

Fig. 10. Comparison of the drive duration with a speed over $100 \mathrm{~km} / \mathrm{h}$ on the motorway section of the test with the limit value (required) and mean values for all vehicles

Analysis of time share data of vehicle parking duration in the urban drive showed that the drive of hybrid vehicle was characterized by the highest value $(29.8 \%)$, and the drive of vehicle fitted with diesel engine with the smallest $(28.6 \%)$. All drives reached the stop time share within the permissible range, i.e. 6\%-30\% (Fig. 11).

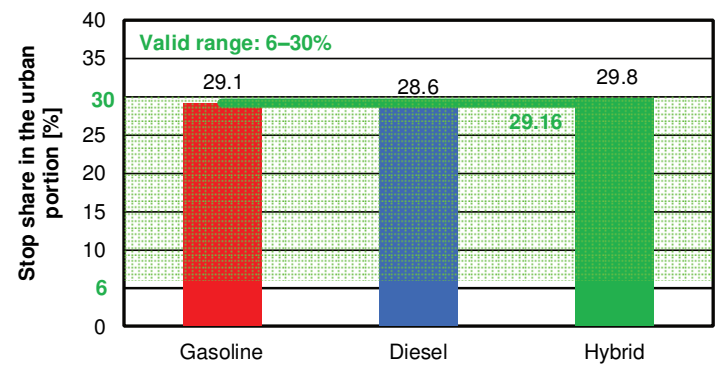

Fig. 11. Share of time spent stationary for the urban portion of the drive test with the limit values (required) and mean values for all vehicles

Analysis of the RPA dynamics data in the urban portion showed that the highest value was achieved by the drive of vehicle fitted with gasoline engine $\left(0.22 \mathrm{~m} / \mathrm{s}^{2}\right)$ and the smallest by drive of hybrid vehicle $\left(0.19 \mathrm{~m} / \mathrm{s}^{2}\right)$. All drives reached value greater than the permissible value based on the average velocity in the urban part (Fig. 12a). The analysis of the RPA dynamics data in the rural portion showed that the highest value was obtained in the drive of vehicle fitted with gasoline engine $\left(0.07 \mathrm{~m} / \mathrm{s}^{2}\right)$ and the others were slightly smaller. All drives reached value greater than the permissible value, e.g. they were valid (Fig. 12b). Analysis of the RPA dynamics data in motorway portion showed the same trend as in the urban part. All drives reached value greater than the permissible value (Fig. 12c). a)

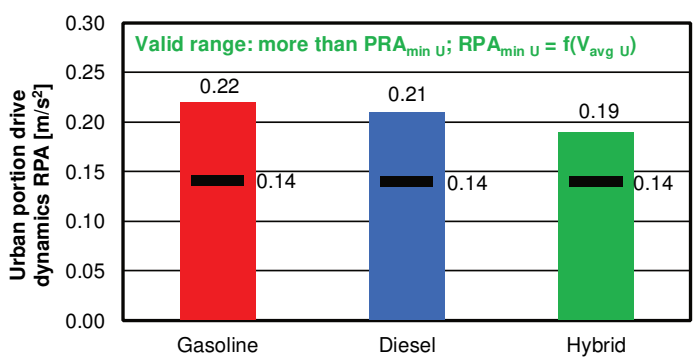

b)

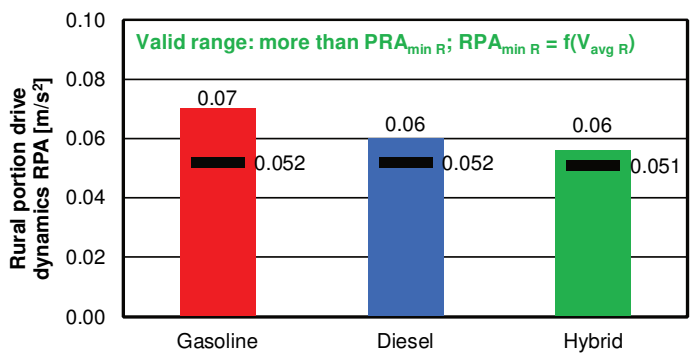

c)

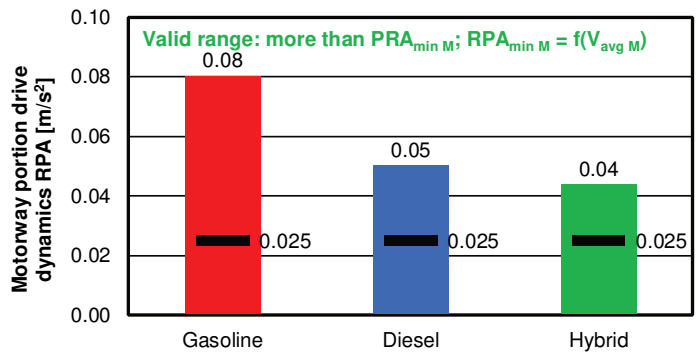

Fig. 12. Relative positive acceleration comparison of urban (a), rural (b) and motorway (c) test drives with the minimum value (required) and the mean value for all vehicles

a)

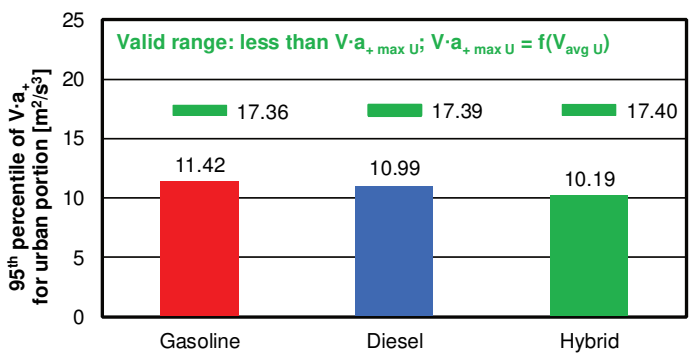

b)

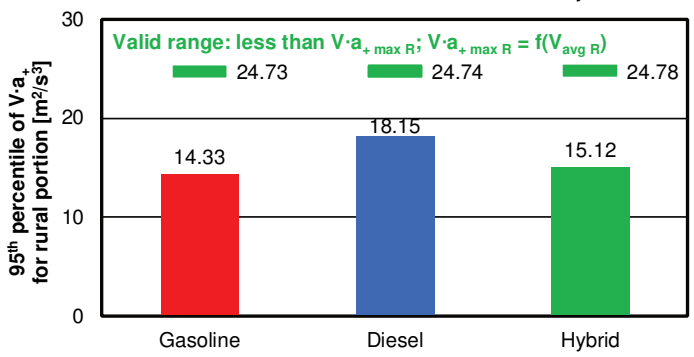

c)

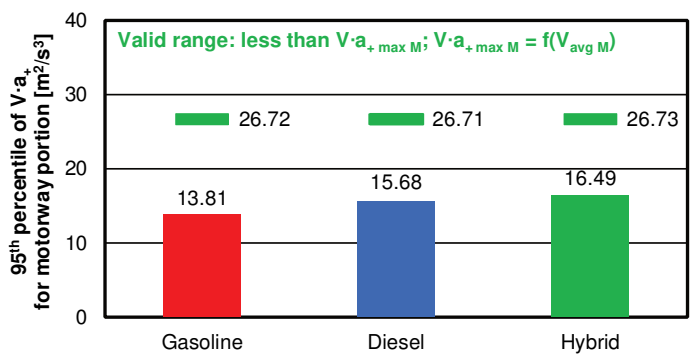

Fig. 13. Vehicle speed and acceleration product $95^{\text {th }}$ percentile comparison of urban (a), rural (b) and motorway (c) test vehicles with the maximum value (required) for all drives 
The analysis of the $95^{\text {th }}$ percentile of $\mathrm{V} \cdot \mathrm{a}_{+}$for the urban portion of the test showed that the highest value was for the drive of vehicle fitted with gasoline engine $\left(11.42 \mathrm{~m}^{2} / \mathrm{s}^{3}\right)$ and the smallest for the drive of hybrid vehicle $\left(10.19 \mathrm{~m}^{2} / \mathrm{s}^{3}\right)$. The values for all the drives were within the acceptable range, i.e. they were less than the maximum determined based on the average velocity in the urban portion (Fig. 13a). In other parts of RDE test the values of this parameter were not exceed, it means they were valid.

\subsection{The impact of dynamic parameters of the RDE tests} on the obtained results of road exhaust emission

The $\mathrm{CO}_{2}$ characteristic curves were determined on basis of the mass of carbon dioxide from WLTC test. It allows to define the measurement windows and then the on-road emission of harmful exhaust components in each part of the RDE test (Fig. 14).

a)

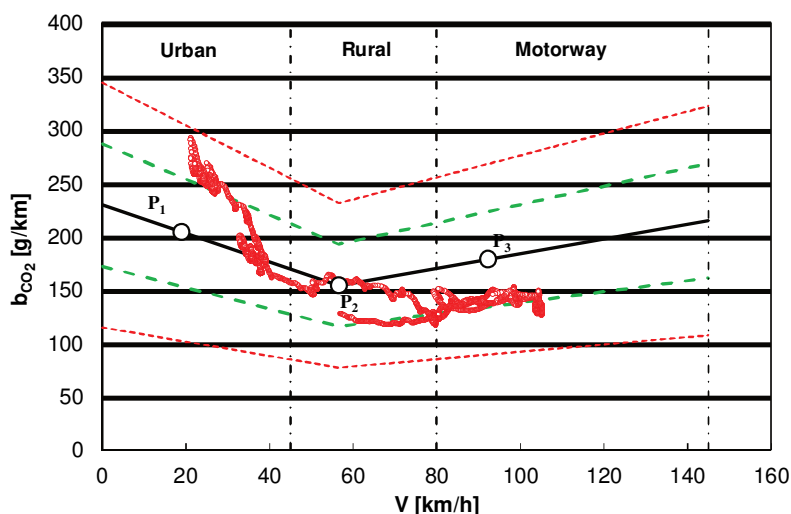

b)

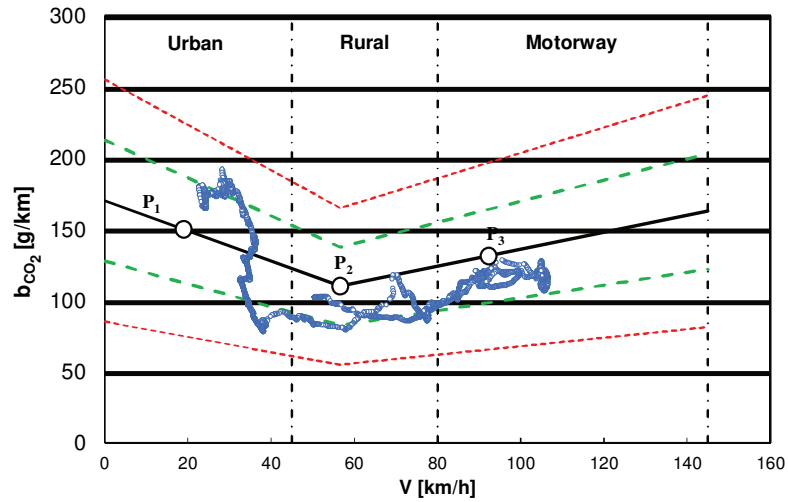

c)

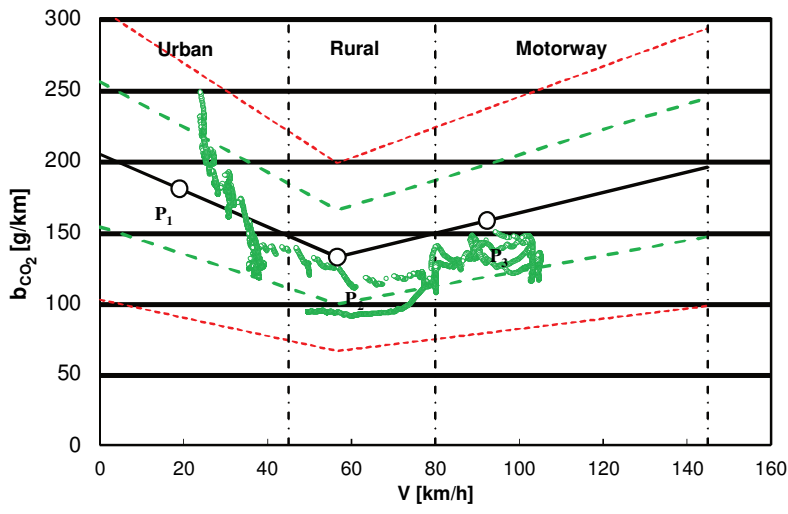

Fig. 14. The carbon dioxides characteristic curves: a) Gasoline, b) Diesel, c) Hybrid
The analysis of the obtained on-road emission values of particular compounds is indicating:

- approximately 10-fold greater road emissions of carbon monoxide both in rural and motorway portion from the vehicle fitted with gasoline engine than from vehicle equipped with diesel engine, and 2-fold greater emission in these conditions as compared to the vehicle with hybrid drive; all vehicles in urban conditions were characterized by similar road emissions of carbon monoxide in range $270-320 \mathrm{mg} / \mathrm{km}$ (Fig. 15a);

- approximately 30-fold greater road emission of nitrogen oxides in each part of the test from vehicle fitted with diesel engine in relation to other vehicles, although in urban conditions the vehicle equipped with diesel engine emits nitrogen oxides twice as many as in other parts of the RDE test (Fig. 15b);

- greater road emissions of carbon dioxide from vehicle with gasoline engine (by 50\%) in comparison to the vehicle equipped with diesel engine - this result was obtained in each part of the RDE test (Fig. 15c);

- similar road emission of particle number for all tested vehicles (Fig. 15d).

Based on the correlation between driving dynamic parameters (relative positive acceleration and product of velocity and positive acceleration) and road exhaust emission in each part of RDE test the curves (Fig. 15, Fig. 16) were determined. They were established for each exhaust compound on the basis of points defining driving dynamics and road emission of the particular compound. The obtained results can be characterized as follows:

- increasing carbon monoxide road emissions with an increase in relative positive acceleration; the largest increase in emissions was for vehicle fitted with diesel engine; 4-fold increase in relative positive acceleration (from $0.05 \mathrm{~m} / \mathrm{s}^{2}$ to $0.21 \mathrm{~m} / \mathrm{s}^{2}$ ) results in 30-fold growth of carbon monoxide road emissions; the smallest increase in emissions of this compound was for vehicle fitted with gasoline engine (by around 50\%);

- increasing nitrogen oxides road emissions with an increase in relative positive acceleration; the largest increase in emission was for vehicle fitted with diesel engine; 4-fold increase in relative positive acceleration (from $0.05 \mathrm{~m} / \mathrm{s}^{2}$ to $0.21 \mathrm{~m} / \mathrm{s}^{2}$ ) results in two-time growth of nitrogen oxides road emissions; the smallest increase in emission of this compound was for vehicle fitted with gasoline engine (by around 50\%);

- increasing carbon dioxide road emissions with an increase in relative positive acceleration, the largest increase in emission was for vehicle with gasoline engine; 3 times increase in relative positive acceleration (from $0.07 \mathrm{~m} / \mathrm{s}^{2}$ to $0.22 \mathrm{~m} / \mathrm{s}^{2}$ ) results in growth of carbon dioxide road emissions by $60 \%$; the smallest increase in emission of this compound was for vehicle equipped with diesel engine (by around 40\%);

- increasing particle number road emissions with an increase in relative positive acceleration; 4-fold increase in relative positive acceleration (from $0.05 \mathrm{~m} / \mathrm{s}^{2}$ to $0.21 \mathrm{~m} / \mathrm{s}^{2}$ ) results in 3 times growth of particle number emissions for all tested vehicles. 
a)

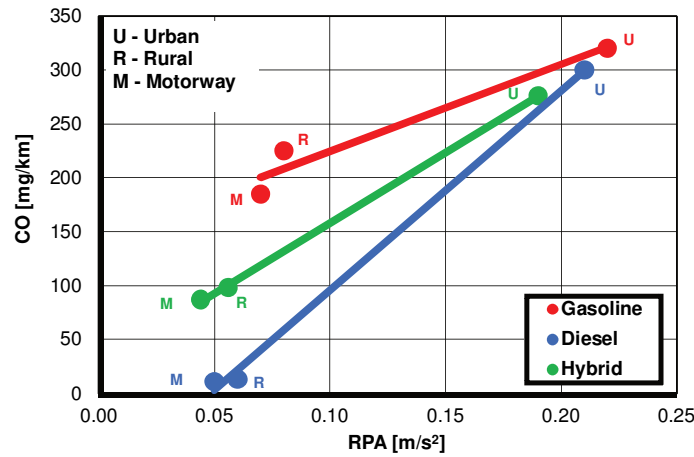

b)

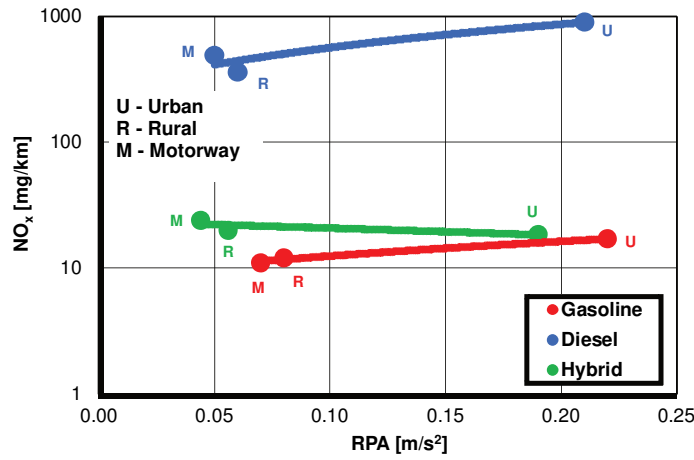

c)

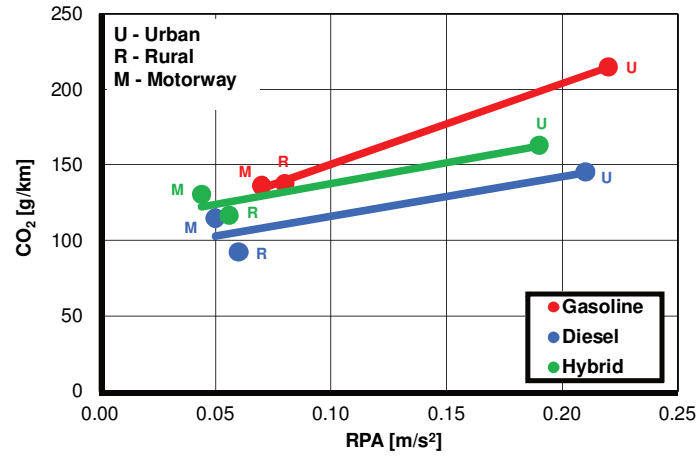

d)

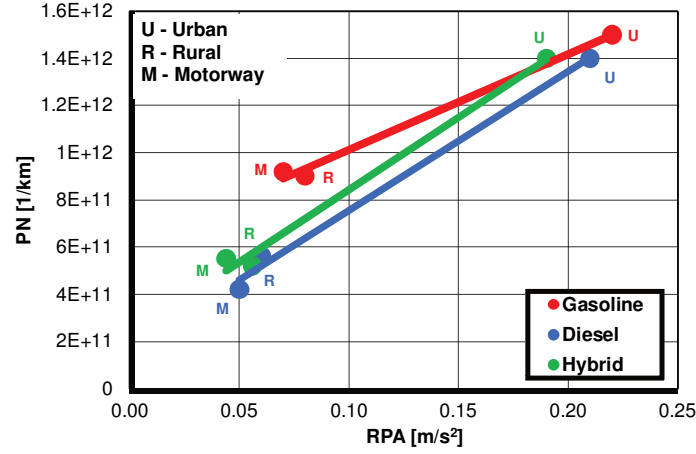

Fig. 15. Correlations between exhaust emissions and relative positive acceleration in particular stages of the test: a) carbon monoxide, b) nitrogen oxides, c) carbon dioxide, d) particle number

The results of relations between road emission and $95^{\text {th }}$ percentile of the velocity and positive acceleration product can be characterized as follows (Fig. 16a-d):

- reduction of the carbon monoxide emissions with an increase of $95^{\text {th }}$ percentile of the velocity and positive acceleration product; an increase of this parameter (from $11 \mathrm{~m}^{2} / \mathrm{s}^{3}$ to the value about $\left.16 \mathrm{~m}^{2} / \mathrm{s}^{3}\right)$, the result in decrease in emissions of carbon monoxide by $50-100 \mathrm{mg} / \mathrm{km}$ at each $2 \mathrm{~m}^{2} / \mathrm{s}^{3}$ of $95^{\text {th }}$ percentile of the velocity and positive acceleration product; this relation was similar to all vehicles; a)

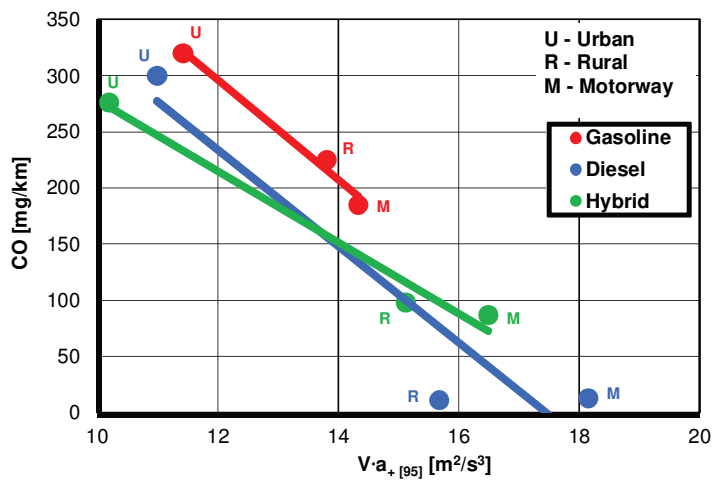

b)

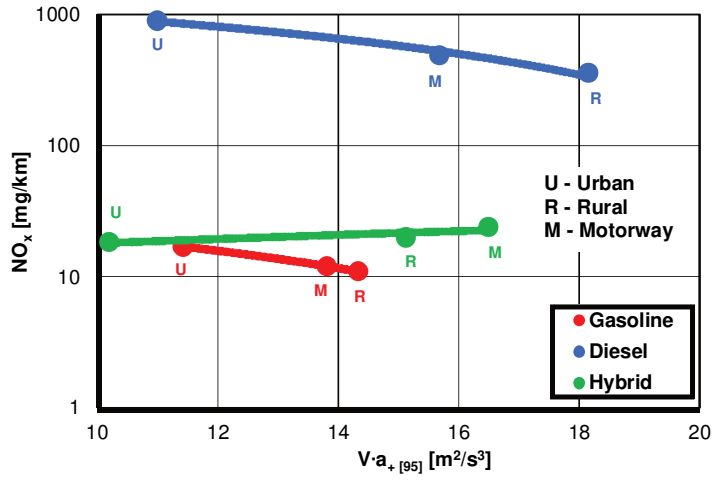

c)

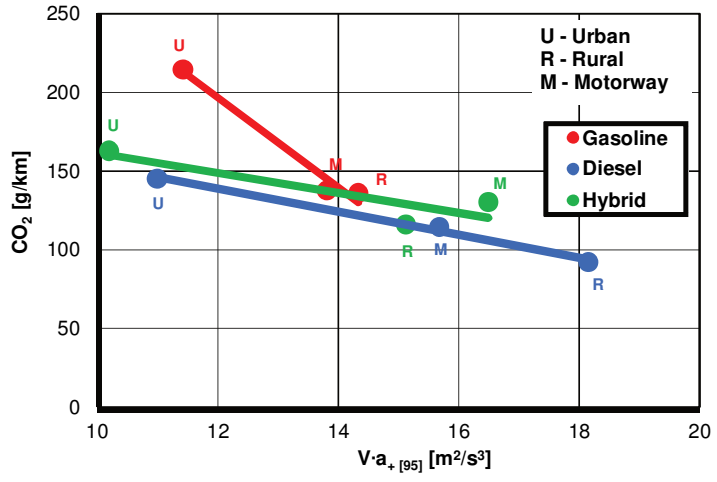

d)

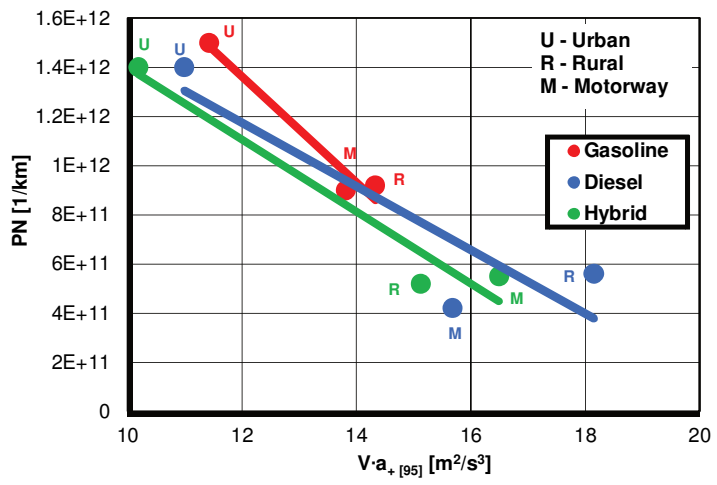

Fig. 16. Correlations between exhaust emissions and $95^{\text {th }}$ percentile of the velocity and positive acceleration product in particular stages of the test: a) carbon monoxide, b) nitrogen oxides, c) carbon dioxide, d) particle number

- reduction of the nitrogen oxides road emissions with an increase of $95^{\text {th }}$ percentile of the velocity and positive acceleration product; for the vehicle fitted with diesel engine an increase of this parameter (from value of $11 \mathrm{~m}^{2} / \mathrm{s}^{3}$ to the value of $18 \mathrm{~m}^{2} / \mathrm{s}^{3}$ ) results in the nitrogen oxides emission by $100 \mathrm{mg} / \mathrm{km}$ at each $2 \mathrm{~m}^{2} / \mathrm{s}^{3}$ of $95^{\text {th }}$ percentile of the velocity and positive acceleration product ; for other vehicles this impact was negligible; 
- reduction of the carbon dioxide emissions with an increase of $95^{\text {th }}$ percentile of the velocity and positive acceleration product; for the vehicle fitted with diesel engine and for the hybrid vehicle an increase of this parameter (from the value of $10-11 \mathrm{~m}^{2} / \mathrm{s}^{3}$ to the value of $17-18 \mathrm{~m}^{2} / \mathrm{s}^{3}$ ) results in decrease in the nitrogen oxides emissions by $50 \%$; for the vehicle fitted with gasoline engine the impact was larger - reduction of the carbon dioxide road emissions from $220 \mathrm{~g} / \mathrm{km}$ to $130 \mathrm{~g} / \mathrm{km}$ by increasing $95^{\text {th }}$ percentile of the velocity and positive acceleration product from value of $11 \mathrm{~m}^{2} / \mathrm{s}^{3}$ to the value of $14 \mathrm{~m}^{2} / \mathrm{s}^{3}$;

- reduction of the particle number emissions with an increase of $95^{\text {th }}$ percentile of the velocity and positive acceleration product; for both the vehicle equipped with diesel engine and hybrid vehicle an increase of discussed parameter (from $10-11 \mathrm{~m}^{2} / \mathrm{s}^{3}$ to $17-18 \mathrm{~m}^{2} / \mathrm{s}^{3}$ ) results in 4-fold decrease in the particle emissions.

\section{Conclusions}

In the fourth quarter of 2018 , new testing procedures for determining the on-road emission of pollutants for motor vehicles entered into force. The European Commission has been working on them for several years, and the changes will be implemented in two steps. In the first phase (by 2020) the RDE tests will be used exclusively for monitoring and in the second phase (after 2020) they will be required as a part of the type approval tests. According to the new research procedure (RDE), determining pollutant exhaust emission is taken place in real driving conditions. Thanks to this solution, the discrepancy between the results obtained in laboratory tests and the results obtained in road tests will be reduced.

The article compares driving test data using the latest legislative proposals for passenger cars. The measurements were performed according to the RDE guidelines for which a minimum test duration of 90 minutes - 120 minutes is required. The obtained results were analyzed in terms of their compliance with the requirements of the RDE procedure. Despite the same research route, not only the results of the velocity profile, but also the average velocity values in each part of the test were varied. The driving parameters defined by acceleration, constant velocity, braking and stopping were similar. With regard to the accuracy of the measurements in actual operation, it should be noted that the final result depends on the operating conditions of the vehicle. However, these conditions (such as traffic congestion, driver's predisposition and his driving style, as well as random events occurring during the drive) are unpredictable.

The analysis of the individual requirements listed in Regulations 427/2016 [4] and 646/2016 [5] confirmed the validity of the RDE test procedure for all tested vehicles. The purpose of the research was to determine the relations between the emission of selected exhaust components and dynamics conditions of the drive. These relations have been confirmed for all tested vehicles and the general conclusions are as follows:

- increasing the relative positive acceleration results in an increase of carbon monoxide, carbon dioxide, and particle number on-road exhaust emission for all tested vehicles;

- increasing $95^{\text {th }}$ percentile of the velocity and positive acceleration product results in a decrease of carbon monoxide, carbon dioxide, and particle number on-road exhaust emission for all tested vehicles.

The study presented in this article was performed within the statutory research (contract No. 05/52/DSPB/0260).

\section{Nomenclature}

a acceleration

$\mathrm{a}_{+} \quad$ positive acceleration

b road exhaust emissions value

CF conformity factor

EOBD European on-board diagnostic

EU European Union

Euro emission standard

GPS global positioning system

OBD on-board diagnostics
PEMS portable emission measurement system

PN particle number

RDE real driving emissions

RPA relative positive acceleration

$\mathrm{S}$ distance

u share

$\mathrm{V} \quad$ velocity

WLTC worldwide harmonized light vehicles test cycle

\section{Bibliography}

[1] Commission Regulation (EC) 443/2009 of the European Parliament and of the Council of 23 April 2009 setting emission performance standards for new passenger cars as part of the Community's integrated approach to reduce $\mathrm{CO}_{2}$ emissions from light-duty vehicles, 2009.

[2] Commission Regulation (EC) 692/2008 of 18 July 2008 implementing and amending Regulation (EC) 715/2007 of the European Parliament and of the Council on typeapproval of motor vehicles with respect to emissions from light passenger and commercial vehicles (Euro 5 and Euro 6 ) and on access to vehicle repair and maintenance infor- mation, European Commission (EC), Official J. European Union, L 199, 2008.

[3] Commission Regulation (EC) $715 / 2007$ of the European Parliament and of the Council of 20 June 2007 on type approval of motor vehicles with respect to emissions from light passenger and commercial vehicles (Euro 5 and Euro 6) and on access to vehicle repair and maintenance information, European Commission (EC), Official J. European Union, L 171, 2007.

[4] Commission Regulation (EU) 2016/427 of 10 March 2016 amending Regulation (EC) No. 692/2008 as regards emis- 
sions from light passenger and commercial vehicles (Euro 6), Verifying Real Driving Emissions, Official J. European Union, L 82, 2016.

[5] Commission Regulation (EU) 2016/646 of 20 April 2016 amending Regulation (EC) No. 692/2008 as regards emissions from light passenger and commercial vehicles (Euro 6), Verifying Real Driving Emissions, Official J. European Union, L 109, 2016.

[6] FEIST, M.D., SHARP, C.A., SPEARS, M.W. Determination of PEMS measurement allowances for gaseous emissions regulated under the heavy-duty diesel engine in-use testing program, Part 1: Project overview and PEMS evaluation procedures. SAE International Journal of Fuels and Lubricants. 2009, 2(1), 435-454.

[7] FONTARAS, G., FRANCO, V., DILARA, P. et al. Development and review of Euro 5 passenger car emission factors based on experimental results over various driving cycles. Science of the Total Environment. 2014, 468-469, 10341042.

[8] FRANCO, V., KOUSOULIDOU, M., MUNTEAN, M. et al. Road vehicle emission factors development: a review. Atmospheric Environment. 2013, 70, 84-97.

[9] KORNISKI, T., GIERCZAK, C., WALLINGTON, T. Laboratory evaluation of the 2.5 inch diameter Semtech ${ }^{\circledR}$ exhaust flow meter with gasoline fueled vehicles. Sensors 4 th Annual SUN Conference. Ann Arbor 2007.

[10] KOUSOULIDOU, M., FONTARAS, G., NTZIACHRISTOS, L. et al. Use of portable emissions measurement system (PEMS) for the development and validation of passenger car emission factors. Atmospheric Environment. 2013, 64, 329338.

[11] LIGTERINK, N., KADIJK, G., VAN MENSCH, P. et al. Investigations and real world emission performance of Euro 6 light-duty vehicles. TNO Report. R11891, 2013.

[12] MAY J., FAVRE, C., BOSTEELS, D. Emissions from Euro 3 to Euro 6 light-duty vehicles equipped with a range of emissions control technologies. Association for Emissions Control by Catalyst. London 2013.

[13] MERKISZ, J., PIELECHA, J. Selected remarks about RDE test. Combustion Engines. 2016, 166(3), 54-61.

[14] MERKISZ, J., PIELECHA, J. The on-road exhaust emissions characteristics of SUV vehicles fitted with diesel engines. Combustion Engines. 2011, 145(2), 58-72.

[15] MERKISZ, J., PIELECHA, J., JASINSKI, R. Remarks about real driving emissions tests for passenger cars. Archives of Transport. 2016, 39(3), 51-63.

[16] Official site of the COPERT 4 Model (2008), http://lat.eng.auth.gr/copert (access: 11.07.2018).

[17] PIELECHA, J., MERKISZ, J., JASIŃSKI, R. et al. Real driving emissions testing of vehicles powered by compressed natural gas. SAE Technical Paper Series. 2015, 2015-01-2022.

Prof. Jacek Pielecha, DSc., DEng. - Faculty of
Transport Engineering, Poznan University of Tech-
nology.
e-mail: Jacek.Pielecha@put.poznan.pl

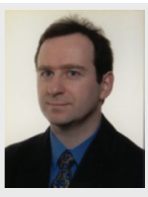

Kinga Skobiej, Eng. - Faculty of Transport Engineering, Poznan University of Technology.

e-mail: Kinga.Skobiej@student.put.poznan.pl
[18] PIELECHA, J., MERKISZ, J., STOJECKI, A. et al. Measu-rements of particles mass, number and size distribution from light-duty vehicles in conditions of variable terrain topography. 19th ETH-Conference on Combustion Generated Nanoparticles. Zurich 2015.

[19] Product Guide, AVL Gas PEMS, AVL List, Graz 2012.

[20] Product Guide, AVL PM PEMS, AVL List, Graz 2012.

[21] RAMOS, A., MUNOZ, J., ANDRES, F. et al. NOx emissions from diesel light duty vehicle tested under NEDC and real-word driving conditions. Transportation Research Part D - Transport and Environment. 20181, 63, 37-48.

[22] Regulation No. 83 on uniform provisions concerning the approval of vehicles with regard to the emission of pollutants according to engine fuel requirements, Addendum 82: Regulation No. 83, Revision 4. United Nations Economic Commission for Europe (UNECE), Geneva, Switzerland 2011.

[23] SHEN, X., SHI, J., CAO, X. et al. Real-world exhaust emissions and fuel consumption for diesel vehicles fueled by waste cooking oil biodiesel blends. Atmospheric Environment. 2018, 191, 249-257.

[24] TRIANTAFYLlOPOULOS, G., KATSAOUNIS, D., KARAMITROS, D. et al. Experimental assessment of the potential to decrease diesel NOx emissions beyond minimum requirements for Euro 6 Real Drive Emissions (RDE) compliance. Science of the Total Environment. 2018, 618, 1400-1407.

[25] UNECE Global Technical Regulation No. 15. Worldwide Harmonized Light Vehicles Test Procedure. UNECE, Geneva, Switzerland, 2015, http://www.unece.org/fileadmin/ DAM/trans/main/wp29/wp29r-1998agr-rules/ECE-TRANS180a15e.pdf (access: 18.06.2018).

[26] UNECE Regulation No. 83 - Revision 5. Uniform Provisions Concerning the Approval of Vehicles with Regard to the Emission of Pollutants According to Engine Fuel Requirements; UNECE: Geneva, Switzerland, 2015, http://www.unece.org/fileadmin/DAM/trans/main/wp29 /wp29regs/r083r4e.pdf (access: 19.06.2018).

[27] User Manual, Semtech DS, On board vehicle emissions analyzer, Sensors Inc., 2008.

[28] VARELLA, R.A., GIECHASKIEL, B., SOUSA, L. et al. Comparison of Portable Emissions Measurement Systems (PEMS) with Laboratory Grade Equipment. Applied Sciences-Basel. 2018, 8, 1633.

[29] WANG, H., GE, Y., HAO, L. et al. The real driving emission characteristics of light-duty diesel vehicle at various altitudes. Atmospheric Environment. 2018, 191, 126-131.

[30] WEISS, M., BONNEL, P., HUMMEL, R. et al. On-road emissions of light-duty vehicles in Europe. Environmental Science and Technology. 2011, 45, 8575-8581.

[31] ZHAO, Q. Electromobility research in Germany and China: structural differences. Scientometrics. 2018, 117, 473-493.

Karolina Kurtyka, MSc., Eng. - Faculty of Transport

Engineering, Poznan University of Technology.

e-mail:

Karolina.T.Kurtyka@doctorate.put.poznan.pl

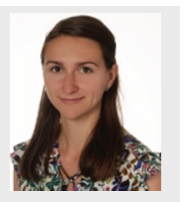

